\title{
The changing conceptions and focus of health research in East Africa
}

\author{
Simon K. Langat and John O. Onyatta \\ Department of Research Development, Ministry of Science and Technology, P. O. BOX 30568 \\ Nairobi, 00100 Kenya

\begin{abstract}
SUMMARY
Perceptions in health research are a product of the circumstances within the society, where the research activities are situated. In East Africa there has been a change in conceptualization over a period of time from an elitist de-linked status to the present, which has evolved to embrace the local community. Here we trace the changes and highlight some occurrences that exerted the greatest influence in shaping the notions that currently dominate in research. We conclude that the paradigm shift is a positive development and that the present conception is suitable for heath research at this point in time.
\end{abstract}

[Afr J Health Sci. 2006; 13:1-6]

\section{Introduction}

A century after scientific research became a feature in economic development in eastern Africa, research paradigms have changed. Today, research is based on the needs of the people, it incorporates community participation, relies on local resources and its output is measured on local applicability to a large extent. The research enterprise responds appropriately to local demands and Governments now consider science and technology an implicit instrument of economic policy [1]

The development of research infrastructure followed a pattern that underscores its relationship to economic development. The first institution to be established in the territory of East Africa was the Veterinary Research Laboratory at Mpwapwa in Tanzania (1884).[2]. In Kenya it was the Forestry Station (1902) followed by the agricultural laboratory (1903). Industrial research made its debut in 1945. Medical research started with the East African Medical Survey of 1949 and the subsequent establishment of the first medical research laboratory in 1958[3] The East African Medical Journal however started publishing in $1923 .^{4} \quad$ Its purpose was to unify the medical profession in East Africa. Its readership quickly spread to other parts of Africa.
During those early years of research in East Africa, research was a handy tool for empire sustenance and colonization policy. The need to open up the hinterland of East Africa for colonial settlers was the fundamental reason for establishing research institutions. Settling immigrants required that the environment be understood; agricultural productivity required improvement and the disease situation had to be managed. The mission of research was therefore to address the issues first from the point of view of the immigrants, then the needs of the unwilling hosts.

Attainment of political independence by the countries of East Africa contributed to the change in the perception and accelerated the process among those involved in research and the communities they serve. Post independence development policy was fast paced and did not have sufficient experience to learn from. Policy- making itself had become participatory and democratic. A larger portion of the population was getting involved and also bringing in a large variety of issues for consideration and requirements to be met by policy. Early post independence policy documents determined that ignorance, poverty and disease were the most important issues for the young governments to address. 


\section{PERSPECTIVE}

The three countries did not establish their own institutions instead they opted to share the facilities earlier set up by colonial authorities. Within the institutions, there had developed a micro culture similar to the founding institutions in Europe. The impact of this state of affairs continued to be felt after political independence.

\section{Historical background}

As mentioned earlier, the East African medical survey was the earliest systematic gathering of data using research methodology. Its aim was to obtain information on the relative importance of the major medical problems in Africa and carry out pilot schemes of control or eradication. ${ }^{5}$ Reports from the survey indicated that there were valuable lessons. In 1951 , the annual report of the colonial office in London recorded that: "...

[T] he scope of and need for medical research in East Africa is unquestionably great, and there are many problems the solution of which would be of marked benefit to the inhabitants of the territories" [6]

The survey was completed in 1958 and its recommendations were received with general acclaim. Inter-territorial and territorial research groups were set up following the recommendations of the survey. The groups developed into research centers and later fully fledged research institutions.

The East Africa Common Services Organization managed the centres. These centres include: the Medical Research Laboratory (Nairobi), the East African Malaria and Vector borne Disease Institute (Amani), the East African Institute for Medical Research (Mwanza), the East African Virus Research Institute (Entebbe), the East African Tuberculosis Investigation Centre (Nairobi), the East African Trypanosomiasis Research Organisation (Tororo) and the East African Tropical Pesticides Research Institute (Arusha). The East Africa Council for Medical Research was the policy organ and existed until the dissolution of the East African Community in 1977. After the Community collapsed, each state established her on infrastructure to guide the development of research within their boundaries. Institutions such as the Kenya Medical Research Institute and the National Institute for Medical Research in Tanzania were created to manage biomedical research entities that existed in their respective territories.

The programmes indicate a strong interest on research following the outcome of the survey. At independence, the interest did not wane, what was of critical importance was the capacity. It is instructive that in 1964 during a conference on international support for research in East Africa the then parliamentary secretary, ministry of Finance in Kenya stated thus:

" In East Africa, we regard research as a necessity, why? Because we live in an environment in which productivity of land, livestock and man is absolutely limited by such physical factors as drought, disease and famine. We rely on research workers to tell us how our scarce resources may be laid out to the best in our fight against poverty and disease and illiteracy... In the fight they are more like front line troops than 'back room boys' that research workers are sometimes called."'[7]

The University of East Africa had a Medical school at Makerere in Uganda. Others In Nairobi and Dar es Salaam did not exist until the 1970's. A pioneer medical researcher in East Africa, the late Joseph M. Mungai noted that traditions that have been followed in the medical schools of East Africa were originally adopted from their former colonial authorities [4]. Likewise, codes of ethics and the basis upon which public health laws were formulated borrowed heavily from the same authority. Research output from the local institutions in Africa found an outlet through journals founded in the former colonial powers. This was a natural course owing to the linguistic ties that had been established. Publishing in international journals had positive effects by way of exposing local scientists to a wide readership and also serving as an indicator that research from the institutions constitutes a respectable contribution to global science. It enables researchers to expand their horizons and speed up their own career development. Disease patterns across the world differ greatly. Within one locality they will also differ at different times reflecting the success or otherwise of 


\section{PERSPECTIVE}

control measures and also the life styles and economic well-being of the population. Other influences were from the local environment, the economy and the public health policy arena. Demands placed on the research system were enormous thus exerting considerable strain on the meager resources available. A wide gap existed between those who generate and store scientific knowledge and those who use it [8]. On the social front; the research system was affected by the inability of the newly independent countries to allow freedom of thought to flourish. Indeed military rule and the similarly repressive single political party status could not let a research system establish common notions with the society it served.

\section{Conceptualization in research}

The main colonial legacy that continues to influence thinking was the fragmentation of indigenous cultures and subsequent dismantling of some [9]. Fragmentation is characterized by rejection of some aspects of a culture and highlighting of others by agents of another based on there understanding. Its impact on health research was distracting; it brought about inadequate development and loss of poise. Research to the public became an alienated private interest of researchers; and to the researcher, an intellectual pastime. Traditional medicine was condemned as witchcraft; anybody advocating its use was ridiculed [10]. Today, in an environment of resource scarcity, ambiguity of policy and an uncertain global commitment to collaboration, there is greater attention being paid to traditional medicine. Since 1984, KEMRI has had a Traditional Disease Research Centre whose function is to establish the origin, methods of preparation, safety and the rationale for incorporating the practice into the formal heath-care system in Kenya [11]. There were other challenges that also contributed to the changing perceptions. The complexity of the issues could not always be understood. There were times of great enthusiasm and times of apathy; away from the upbeat enthusiasm of the possibility of eradicating diseases that followed the outstanding discoveries, we came to the era characterized by emergence and re-emergence of diseases. The following statements attributed to senior managers of public health programmes illustrate the swing from fervour to despair appropriately.

1925

"The problem of colonization of Africa is the problem of malaria...and malaria is far and away the disease of outstanding importance in Kenya, both from the point of view of the mortality it causes, and the chronic debility attributable to it".

J. L. Gilks, Director of Medical Services Nairobi, Colony of Kenya

1947

"...with the discoveries of new antimalaria drugs and powerful insecticides there are new possibilities before us to control this greatest of scourges (malaria) of the tropics!. That era, I reckon is just round the corner, and the subject of malaria will be a thing of the past." J.P. de Mello, General Practitioner \& Malariologist, Nairobi, Colony of Kenya.

\section{8}

"...there is an urgent need for new tools in malaria control. But it must be added with regrets that in tropical Africa the control measures possible and available have not been fully utilized or exploited and excess mortality from malaria is going to occur."

G. B. A. Okelo, Director of Medical Services Nairobi, Republic of Kenya.

\section{Source: Ministry of Health-Malaria: a situation analysis[12]}

In analyzing the fundamental notions upon which biomedical research in East Africa is founded, we use the above example from malaria to highlight the swing of optimism between two extremes. This was not peculiar to malaria; the situation was similar in many other diseases. What is noteworthy is that during the same period mankind made the greatest strides in biomedical sciences. The disparities in health and wealth widened in the $20^{\text {th }}$ century [13]. Research spending went up while the gains in practice were not commensurate. The Kenya Government in its policy paper; The Economic Strategy for Wealth and Employment Creation stresses the need to address fundamental concerns in 


\section{PERSPECTIVE}

health in order to improve the now deteriorating health situation (2003) [8].

\section{Formative influences}

Perceptions and paradigms in research are a result of influence from at least three sources: global, regional or local. The Alma- Ata declaration in 1978, intended to achieve health for all through primary health care [14]. Countries took up the challenge of an equity oriented health strategy with a sense of urgency (it was to be achieved by the year 2000). The strategy recorded uneven progress with developing countries doing worse [15]. In the last decade of the twentieth century, when it was apparent that Alma- Ata declaration could not be achieved, the report of the Commission on Health Research for Development became the next most influential document in research circles. It advanced the idea that an integrated strategy was required for the attainment of the goal of health for all. The concept was named Essential National Health Research (ENHR) and would involve communities, researchers and policy and decision makers [16]. The 10/90 disequilibruim was highlighted and the Global Forum was born. At the same time, there was a gradual shift of vision in health provision that the World Health Organization (WHO) termed: "New Universalism." In this approach, health care was to be limited to only the simplest and most basic form and only to the poor [17]

Regional sources of influence are found in regional collaboration like the south-south initiatives etc. In Africa, the idea of an African renaissance is gaining ground. It forms the basis of such initiatives like the New Programme for African Development (NEPAD). Such initiatives serve the purpose of ensuring that greater involvement of local expertise in order to benefit from complementarity of programmes and cub duplication. The NEPAD programme focuses on regional collaboration, promotes centres of excellence and use of local expertise for consultancies and capacity building. Exchange of information and joint programmes in the region has recently been shown to be useful for the furtherance of research. It is becoming apparent that neighbouring countries have plenty to share, language barriers not withstanding. In the past countries could only collaborate with those of which they had colonial ties. This was yet another effect of colonialism which countries and their systems in Africa have to unlearn.

Within the country, interaction with communities and the inertia attributable to growth of research as a sector have a great impact on the research system. Growth refers to: widening of experiences of researcher and research managers, numerical growth in all indicators of capacity (human resources, facilities, programmes and financing), closer interactions with the education sector and other sectors. The environment determines the level of public support research would receive. Global interaction also influences at a lower level; through collaboration programmes with funding agencies from the north and technology transfer programmes. Research has to listen to the local community and seek solutions for the community from within. A research system in a country has an obligation to the community, within which it is located. It is bound by a 'social contract' to support the community in looking for ways of improving its health. The responsibility of the research system is to influence policy positively, ensure that there are no neglected areas in disease control and work towards the adoption of the results it produces.

\section{Appropriate approaches to health research}

The framework of thought determines research thrust. As an illustration we take another look at malaria research: In the mid years of the twentieth century, after the discovery of malaria transmission, research focused on the development of tools to eliminate the vector. Cheap insecticides and DDT were used and even the WHO declared that eradication of malaria was nigh during its assembly in 1956 [18]. Two decades later, experience had shown that the control of malaria required more than was on offer. The focus changed to using the approaches provided by developments in the basic sciences. Today the search for vaccines is ranked highly while it is now clear that it will take multiple approaches to control malaria. Balancing research 


\section{PERSPECTIVE}

priorities in malaria research alone requires an evaluation of all the issues above and also the perception of the researchers themselves. This should lead to noticeable changes in research and new. The applicability of results will be improved, second, there will be greater demand for research and third research will become the driving force in development. These changes can be seen at present. For example: that traditional medicine is getting greater attention, the holistic approach to health provision is increasingly gaining acceptance in the region, and that reviewers of protocols are now more likely to take into account community needs and consider them with more than passing interest. The foreign input too, is subjected to vetting for local value adding and subtle features that sustain inequality.

That research should aim at local problems and seek local applications cannot be gain said. In circumstances where funding is hardly sufficient for programmes, prioritization must be carefully done. The focus must be only on what is achievable, relevant and valid. Authorization and clearance must approach each request with care. Institutions insist on a robust scientific methodology, value to the local community and sound justification of each component in the protocol. The impact of these stringent requirements to a large extent shapes the thoughts of researchers. Once it becomes natural for them to pursue good science and well-written protocols, the effect spreads to funding agencies and the public. A positive result of this would be more funding and greater acknowledgement of research activities. This acknowledgement would bring about new sources of funding like local philanthropy. While it is currently unheard of that people dedicate any money for research locally, it is important to cultivate it. Some scientific topics are best funded through private interest, as public funds will always be competitive and never wholly sufficient. Lobby groups and activism will play an increasing role in influencing the flow of resources to research programmes. They will get louder and louder to a point where they will determine outcomes in priority setting. This is what obtains in the HIV/AIDS arena when we look at the global scene. It remains to be seen how it will project itself in the East African context.

\section{Conclusion}

The infrastructure left behind by the British colonialism has moved on to underline its relevance. The local research effort has borne fruit and holds the promise of delivering expected results. Critical areas often overlooked at the global level are the constituency of the local research enterprise. Emphasis must be on contemporary issues and in ways that the existing health service provision can readily utilize. Research management now has the support of sufficiently experienced organs for review and policy execution. There is a general agreement as to what the ideals of a heath research system should be. This is favourable to the extent that research has before it, the huge task of addressing urgent matters of the region including otherwise neglected disease conditions.

\section{References}

1. NCST; Science \& Technology for Development; NCST Report No 4, 1980

$\mathrm{p}(\mathrm{v})$

2. Kohi Y. M. Science \& Technology Policy in Tanzania. Science and Technology Policy in E.A: Country Papers and Comparative Review. East African Community, Arusha . 2002 p 106.

3. Oduwo R.N. Institutional Arrangements for Health Research in Kenya: Proceedings of the Convention on National Health Research: 1994. p 12

4. Mungai J.M. Research publications are important performance indicators of university medical education in African countries. African Journal of Health Sciences. 1998; 5:50-57.

5. Colonial Office, Annual Report of the East Africa High Commission 1950: His Majesty's Stationery Office London 1951:p47.

6. Colonial Office, Annual Report of the East Africa High Commission 1954 Her 


\section{PERSPECTIVE}

Majesty's Stationery Office London 1955: pp52-53.

7. Anonymous. Conference on International Support for Research in East Africa. East Africa Common Services Organization. 1964. p14.

8. Government of Kenya. Economic Recovery Strategy for Wealth and Employment Creation 2003-2007, Government Printer, 2003. p56

9. Anonymous. International Conference on Health Research for Development: Regional Consultative Process for Africa. Bangkok . 2000; p6,23

10. Thairu K. The Direction of Medical Research in Africa, in Were J. B. O. Mutugi M. W. and Githure J. I. (Eds.) Proceedings of the Annual Medical Scientific Conference. 1992; 13 Part :.6

11. Kenya Medical Research Institute. Annual Report. 1988-89 p15.

12. Snow R (Editor), Ministry of Health = Malaria: a situation analysis. Govrnment Printer, Kenya 1998. pv

13. Benatar S. R. Reflections on Research Ethics in Developing Countries. Social Science and Medicine. 2002; 54;11311141

14. WHO, Declaration on Primary Health Care, Report of the International Conference on Primary Health Care. Alma- Ata.1978; pp2-6.

15. Task Force on Health Research for Development: A strategy for Action in Health and Human Development. UNDP, 1991. p1

16. Commission on Health Research for Development. Health Research: Essential Link to Equity in Development: Oxford University Press, p 190.

17. WHO. World Health Report 2000. Health systems: Improving Performance; 2000

18. Kitua A. Y. The future of malaria research and control: An African perspective; African Journal of Health Sciences. 1998; 5: $58-62$ 